\title{
Efectos de la densidad de cultivo y de elementos de refugio en el crecimiento y supervivencia de juveniles de centollo, Maja brachydactyla (Balss, 1922)
}

\author{
Effects of culture density and shelter on growth and survival of juvenile spider crab, \\ Maja brachydactyla (Balss, 1922) \\ Pedro Domingues $^{1}$ y Javier Alaminos ${ }^{1}$ \\ ${ }^{1}$ IFAPA Centro Agua del Pino, Carretera Cartaya-Punta Umbría, s/n.21450 Cartaya, Huelva, España \\ fjavier.alaminos@juntadeandalucia.es
}

\begin{abstract}
The effects of culture density (11 and 50 spider crabs $\mathrm{m}^{-2}$, respectively) and shelter (presence or not of macro algae in the trays) on survival of 2 months old juvenile spider crabs ( $M$. brachydactyla) were tested. All groups were fed boiled and frozen mussels (Mytilus sp.) ad libitum, during the entire experiment. After 60 days, in the experiment I, survival of spider crabs cultured at the lower density was $83.3 \pm 19.3 \%$, significantly higher $(P<0.05)$ compared to the ones cultured at the higher density, with a $14.3 \pm 5.8 \%$ survival. In the experiment II, survival of spider crabs in the presence / absence of macro algae (Ulva lactuca) as refuges, was not significantly different $(P>0.05)$ (33.3 $\pm 19.2 \%$ and $37.0 \pm 20.2 \%$, respectively). The final density of spider crabs in all trays, after 60 days of experimentation, was similar to the lower density tested (11 spider crabs $\mathrm{m}^{-2}$, equivalent to 3 spider crabs $\mathrm{m}^{-2}$ ). This density seems to be appropriate for the culture of juvenile spider crab, in the defined culture conditions $\left(T=20 \pm 2^{\circ} \mathrm{C}\right.$, natural photoperiod corresponding to the months between September and March in a latitude of $37^{\circ} 13^{\prime} \mathrm{N}$, and salinity close to 35 ups). Growth rates in weight (g) and carapace length (mm), when feeding on boiled and frozen mussels were of $2.1 \pm 0.7 \%$ $\mathrm{BW} \mathrm{d}{ }^{-1}$, and of $0.6 \pm 0.3 \% \mathrm{BW} \mathrm{d}^{-1}$ respectively.
\end{abstract}

Key words: Culture, density, growth, Crustacea
Resumen.- Se probaron los efectos de la densidad de cultivo (11 y 50 individuos $\mathrm{m}^{-2}$, respectivamente) y refugio (presencia o no de macroalgas en las bandejas) en la supervivencia de juveniles de centollo ( $M$. brachydactyla) de dos meses de edad. Todos los grupos se alimentaron con mejillón (Mytilus sp.) cocido y congelado, añadido ad libitum durante todo el experimento. Al cabo de 60 días, en el experimento I, la supervivencia en las cubetas de baja densidad fue del $83,3 \pm 19,3 \%$, significativamente más alta $(P<0,05)$ que el cultivo de alta densidad, con una supervivencia de $14,3 \pm 5,8 \%$. En el experimento II, la presencia o ausencia de macroalgas (Ulva lactuca) como refugios, no resultó en una supervivencia significativamente diferente $(P>0,05)(33,3 \pm 19,2 \%$ y $37,0 \pm 20,2 \%$, con algas y sin algas, respectivamente). Al término de los 60 días de experimentación, la densidad de los centollos en todas las cubetas fue similar a la empleada en la menor densidad del primer experimento (11 centollos $\mathrm{m}^{-2}$, equivalentes a 3 centollos por cubeta). Esta densidad parece ser apropiada para el cultivo de juveniles de centollo, en las condiciones de cultivo empleadas $\left(T=20 \pm 2{ }^{\circ} \mathrm{C}\right.$, fotoperiodo natural correspondiente a los meses entre septiembre y marzo en una latitud de $37^{\circ} 13^{\prime} \mathrm{N}$ y salinidad cercana a $35 \mathrm{ups}$ ). Las tasas de crecimiento en peso (g) y longitud del caparazón (mm), utilizando el mejillón cocido y congelado como alimento, fueron de $2,1 \pm 0,7 \%$ día y de $0,6 \pm 0,3 \%$ día, respectivamente.

Palabras clave: Cultivo, densidad, crecimiento, Crustacea

\section{Introducción}

El centollo (Maja brachydactyla Balss, 1922) es una especie con un alto valor en el mercado (Sampedro et al. 2003), cuya distribución natural se extiende por la costa este del Océano Atlántico, desde el Mar del Norte hasta el Golfo de Guinea, y por el Mar Mediterráneo (Ingle 1980, Kergariou 1984, Le Foll 1993). El ciclo de vida de esta especie es complejo, con unos requerimientos vitales y comportamiento que varían significativamente con la edad, tamaño y modo de vida de cada individuo (González-Gurriarán \& Freire 1994, González-Gurriarán et al. 2002). Las especies del género Maja presentan segregación espacial entre sexos, juveniles y adultos y estados reproductivos (González-Gurriarán \& Freire 1994, González-Gurriarán et al. 2002).

Los crustáceos crecen normalmente de manera discontinua, evidenciando saltos de tamaño causados por el proceso de muda, en el que se produce un recambio del exoesqueleto antiguo por otro mayor. En este proceso, que se denomina ecdisis (Chang 1989), intervienen muy diversos factores de carácter interno (hormonales, estado nutricional, etc.) y externos o ambientales (temperatura, 
fotoperiodo, etc.). La dieta de los estados juvenil y adulto en estado silvestre es variable y compuesta principalmente por macroalgas, moluscos y equinodermos (Bernárdez et al. 2000). Los juveniles de Maja sp. habitan aguas poco profundas, de no más de 15 metros de profundidad, con sustratos arenosos y/o rocosos (Hines et al. 1995). La madurez sexual se produce tras la denominada muda terminal, que tiene lugar durante el verano en juveniles de unos dos años de edad (González-Gurriarán et al. 1995). La reproducción ocurre entre mayo y septiembre, cuando la mayoría de las hembras se encuentran ovígeras. En cautividad se han observado puestas durante 3-4 veces consecutivas con una única intervención del macho (Iglesias et al. 2002).

Contrariamente a la mayoría de los crustáceos, el centollo se caracteriza por un ciclo de vida dividido en dos etapas, separadas por la denominada muda terminal (Conan et al. 1992, Sampedro et al. 1999). En la primera etapa, el ciclo de vida se caracteriza por una fase de crecimiento somático, como consecuencia de varias mudas, que provocan un crecimiento escalonado del individuo (Carlisle 1957, Hartnoll 1963), mientras que tras la muda terminal, se produce la maduración del individuo y se entra en la fase adulta, cuando el individuo deja de crecer (Sampedro et al. 2003). Según Sampedro et al. (1999), esta muda terminal ocurre cuando los individuos, tanto machos como hembras, alcanzan un tamaño del caparazón entre 114 y 164 mm.

Uno de los factores clave en la acuicultura es optimizar el crecimiento en un mínimo de espacio (Forsythe et al. 2002, Iglesias et al. 2002, Domingues et al. 2003) evitando una excesiva masificación de individuos, que puede tener efectos negativos sobre el crecimiento y el comportamiento de muchas especies. La densidad de cultivo es pues un factor muy importante en acuicultura (Sumpter 1993). Aunque la manera más común de expresar la densidad óptima es la denominada capacidad de carga, definida como el número máximo de individuos que pueden ocupar un espacio de manera sostenible, también pueden existir otros aspectos de máxima importancia para la evolución del cultivo, tales como alteraciones en el comportamiento por una alta masificación (Boal et al. 1999).

Iglesias et al. (2002) obtuvieron centollos adultos (supervivencia del 66\%) con longitud del caparazón de $6,5 \pm 0,8 \mathrm{~cm}$ a los 9,5 meses de edad, en condiciones de cultivo semi-intensivo, con temperaturas entre 15 y $18^{\circ} \mathrm{C}$, aunque en cultivo intensivo la supervivencia fue baja $(0,7 \%)$ y el crecimiento significativamente menor. No obstante, el simple hecho de haber existido una alta tasa de crecimiento a bajas temperaturas de cultivo, hace del centollo una buena opción como especie alternativa al cultivo de otros mariscos como los peneidos, de rápido crecimiento en zonas tropicales de altas temperaturas, donde se pueden obtener hasta dos cosechas anuales. Esta elevada productividad se ha traducido en una feroz competencia al cultivo de estas especies en aguas más frías como las templadas de España y sur de Europa, donde prácticamente se ha abandonado el cultivo industrial de peneidos.

El objetivo del presente trabajo fue determinar el efecto de la densidad de cultivo y de la presencia de refugios (para disminuir la probabilidad de encuentros) en la supervivencia de juveniles de centollo. También y sólo para comprobar la calidad nutricional del mejillón cocido y congelado, se han analizado las tasas de crecimiento utilizando esta dieta como alimento.

\section{Material y métodos}

Se realizaron dos experimentos utilizando juveniles de centollo nacidos en el Centro IFAPA Agua del Pino, procedentes de puestas efectuadas por hembras capturadas directamente del medio natural, en las costas de Huelva (zona atlántica sur occidental de la Península Ibérica, $37^{\circ} 13^{\prime} \mathrm{N}$ y $7^{\circ} 5^{\prime} \mathrm{O}$ ) durante el mes de junio ( $\mathrm{T}$ media del agua del mar: $\left.20,9 \pm 0,7^{\circ} \mathrm{C}\right)$. En cada experimento, considerado individualmente, los juveniles usados fueron todos de la misma hembra y pertenecientes a una misma puesta. No obstante, por separado, los individuos del experimento I y los individuos del experimento II pertenecían a puestas distintas y tenían edades y tamaños distintos, aunque iguales entre sí, como se indica anteriormente. Todos los experimentos se realizaron con un fotoperiodo natural, correspondiéndose éste con el de los meses entre septiembre y diciembre de 2006, en las latitudes medias del sur de España (15/9 h luz/oscuridad), con una temperatura controlada en laboratorio de $20 \pm 2^{\circ} \mathrm{C}$ y una salinidad de $35 \pm 2$ ups. En ambos experimentos, de 60 días de duración, se utilizó como alimento mejillón (Mytilus sp.) cocido y congelado. Los pesos se registraron con una balanza de precisión de tres decimales (COBOS CB compelt(C), y la longitud del caparazón se determinó con un calibre electrónico de precisión (MITUTOYO Absolute coolant Proof. IP66@), de dos decimales.

\section{Experimentos sobre densidad}

En ambos experimentos se usó un sistema de bandejas de cultivo de $0,28 \mathrm{~m}^{2}$ de superficie de fondo $(80 \mathrm{x} 35 \mathrm{~cm})$ y una profundidad de agua de $15 \mathrm{~cm}$ (volumen total de $42 \mathrm{~L})$. Se utilizó un flujo abierto de alto caudal (54 $\mathrm{L} \mathrm{h}^{-1}$ ), para asegurar una total renovación del agua en menos de una hora. 
También en ambos casos se registraron diariamente la existencia de exuvias (indicativas de mudas) y de animales muertos, para esclarecer una posible relación entre ambos sucesos, ya que la muerte de un individuo tras la muda puede tener su origen en causas naturales (estrés durante el proceso de muda) o en episodios de canibalismo (tras la muda el animal queda indefenso frente a la depredación por otros centollos, hasta que se endurece su nuevo caparazón).

Las tasas individuales de crecimiento se calcularon sobre datos quincenales de peso y longitud del caparazón, tomados de los individuos de las cuatro bandejas con baja densidad de centollos.

\section{Experimento I}

Se utilizó un total de 68 juveniles de centollo de dos meses de edad, con un peso individual comprendido entre $0,2 \mathrm{y}$ 1,2 g. Para determinar los efectos de la densidad sobre la supervivencia, estos individuos se distribuyeron en cuatro bandejas con tres centollos cada una y otras cuatro bandejas con 14 centollos cada una, dando como resultado densidades de 11 y 50 individuos $\mathrm{m}^{-2}$, respectivamente. Diariamente se contabilizó el número de individuos en cada prueba y se registró la presencia de mudas y posibles restos de canibalismo.

Como alimento se utilizó mejillón (Mytilus sp.) cocido y congelado, proporcionado ad libitum. Diariamente se retiraron los restos de alimento del día anterior y se añadió la ración correspondiente a saciedad.

Los datos se analizaron mediante la prueba t de Student, para determinar diferencias en la supervivencia debidas al tratamiento y previamente se comprobó que cumplían los requisitos de normalidad y homoscedasticidad (Zar 1984).

\section{Experimento II}

Para este experimento se utilizó un total de 54 juveniles de centollo de un mes de edad y con un tamaño similar $(P>0,05)$, de $0,014 \pm 0,04 \mathrm{~g}$. Se hicieron seis replicados en seis bandejas distintas con nueve centollos cada una, resultando una densidad de 32 centollos por $\mathrm{m}^{2}$ en todos los casos. En tres replicados se añadieron macroalgas (Ulva lactuca) a modo de refugios para ocultar a los individuos recién mudados, protegiéndolos del posible canibalismo. El seguimiento que se realizó fue el mismo que en el experimento I, es decir, diariamente se registró el número de individuos por bandeja, la presencia de mudas y posibles restos de canibalismo. Como en el experimento anterior se proporcionó como alimento mejillón cocido y congelado ad libitum. Se comprobó que todos los datos cumplían los requisitos de normalidad y homoscedasticidad y se empleó la prueba t de Student para determinar posibles diferencias en la supervivencia (Zar 1984).

\section{Experimento sobre crecimiento}

A su vez, los cuatro replicados de tres centollos por bandeja utilizados en el experimento I, se eligieron para estudiar la tasa de crecimiento empleando mejillón cocido y congelado como alimento y comprobar su calidad como dieta. Cada 15 días se determinó el peso y la longitud del caparazón, calculándose la tasa de crecimiento como: TC $\left(\%\right.$ peso día $\left.{ }^{-1}\right)=((\mathrm{LnP} 2-\mathrm{LnP} 1) / \mathrm{t} \times 100)$, donde $\mathrm{LnP}$ es el logaritmo neperiano de los pesos inicial (1) y final (2) y $\mathrm{t}$ el tiempo transcurrido entre los momentos 1 y 2, expresado en días. El protocolo de trabajo consistió en la captura del juvenil de centollo con una cucharilla, su depósito sobre un papel de filtro durante unos segundos para eliminar el exceso de agua y seguidamente proceder a determinar su peso. Se comprobó que todos los datos cumplían los requisitos de normalidad y homoscedasticidad. Posteriormente se analizaron los datos aplicando análisis estadísticos (ANOVA) (Zar 1984) para determinar posibles diferencias en el crecimiento de los juveniles de centollo.

\section{Resultados}

\section{Estudios sobre densidad}

En la Fig. 1 se presentan los valores de la supervivencia de los centollos en el experimento I, a las dos diferentes densidades de cultivo probadas: 11 centollos $\mathrm{m}^{-2}$ y 50 centollos $\mathrm{m}^{-2}$. Hasta el día 50 la supervivencia a la más baja densidad fue del 100\%; entre los días 50 y 60 murieron dos centollos en los replicados 1 y 2; la supervivencia final fue de $83,3 \pm 19,3 \%$, significativamente más alta $(P<0,05)$ que la obtenida en el cultivo de alta densidad (14,3 $\pm 5,8 \%)$. La mortalidad fue baja en la prueba de baja densidad, siendo $37,5 \pm 47,9 \%$ el porcentaje de individuos que murieron después de la muda, lo que, asimismo, refleja una escasa incidencia de canibalismo, más acusada si consideramos el total de individuos presentes en la densidad de 11 centollos $\mathrm{m}^{-2}$, resultando inferior al 5\%. Por el contrario, la mortalidad después de la muda fue muy alta en la prueba de alta densidad (57,9 $\pm 13,3 \%$ de los individuos muertos presentaron signos de canibalismo), traduciéndose este dato en un porcentaje del $30 \%$, considerando el total de individuos de la densidad de 50 centollos $\mathrm{m}^{-2}$. Asimismo, la aplicación de análisis estadísticos a estos datos concluyó que la mortalidad después de la muda fue significativamente diferente $(P<0,05)$ según las dos densidades probadas (11 y 50).

En la Fig. 2 se muestran los datos de la supervivencia de los juveniles de centollo en el experimento II, donde 


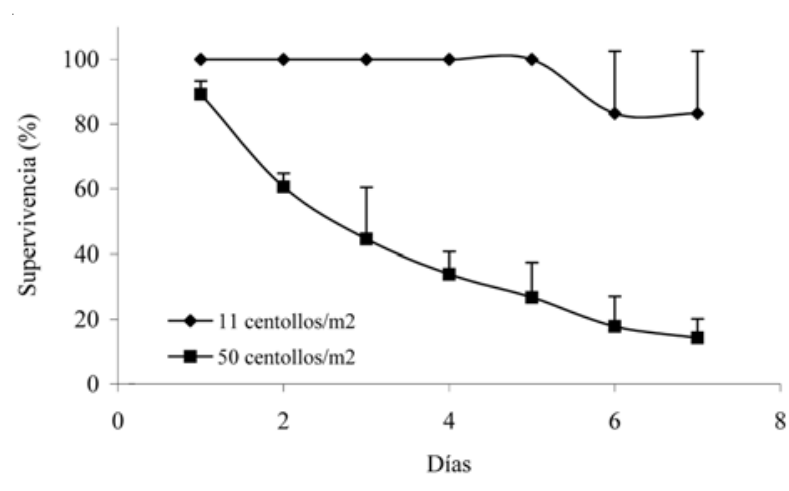

Figura 1

Supervivencia de juveniles de centollo cultivados a diferentes densidades. Barras = desviación estándar

Survival of juvenile spider crabs cultured at two different densities. Bars $=$ standard deviation

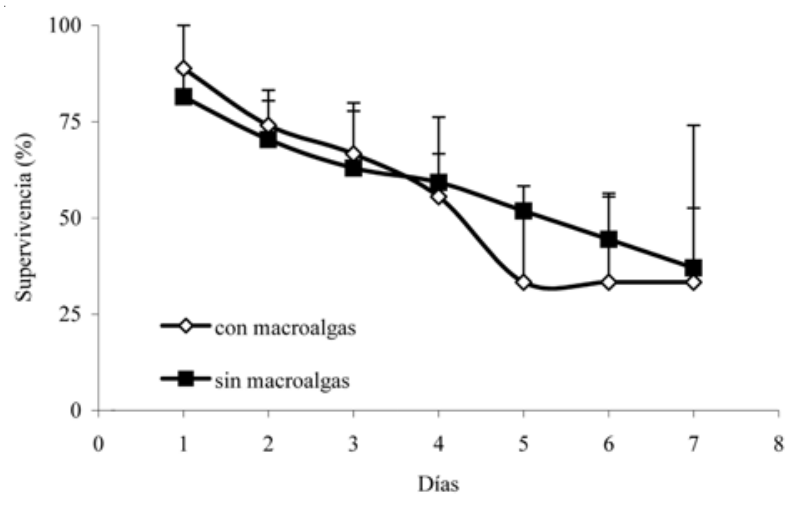

Figura 2

Supervivencia de juveniles de centollo cultivados con y sin macroalgas como elementos de refugio. Barras = desviación estándar

Survival of juvenile spider crabs cultured with and without macroalgae. Bars = standard deviation

se probó la capacidad de utilización de macroalgas como elementos de refugio para centollos recién mudados y su utilización como fuente de alimento complementaria. No hubo diferencias significativas $(P>0,05)$ en la supervivencia de los centollos en cada caso $(33,3 \pm 19,2$ y 37,0 $\pm 37,0 \%$, respectivamente). La relación entre el proceso de muda y la mortalidad fue similar en las

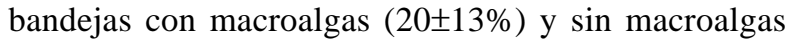

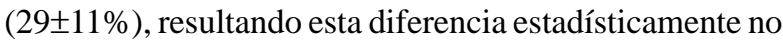
significativa $(P>0,05)$. La mortalidad causada por canibalismo después de la muda fue baja en ambos grupos $(<10 \%)$ y no estadísticamente diferente $(P>0,05)$.

\section{Estudios sobre crecimiento}

Los centollos incrementaron su peso desde $0,3 \pm 0,1 \mathrm{~g}$

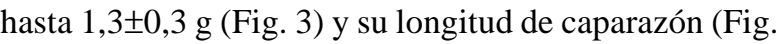
4) desde $9,0 \pm 0,2 \mathrm{~mm}$ hasta 14,3 $\pm 1,1 \mathrm{~mm}$, durante los 60 días que duró el experimento. Sin embargo, cuando se han comparado estadísticamente estos resultados al final del experimento, no arrojaron diferencias significativas $(P>0,05)$ ni en cuanto a peso ni en cuanto a longitud del caparazón, entre los cuatro replicados, lo que era de esperar dado que fueron alimentados con la misma dieta. Las tasas de crecimiento relativas al peso durante los 60 días del experimento, fueron de 2,3 $40,9 \% \mathrm{P} \mathrm{d}^{-1} ; 2,6 \pm 0,7 \%$ $\mathrm{P} \mathrm{d}^{-1} ; 2,1 \pm 0,8 \% \mathrm{P} \mathrm{d}^{-1}$ y $2,4 \pm 0,6 \% \mathrm{P} \mathrm{d}^{-1}$, respectivamente, para cada uno de los cuatro replicados, no existiendo

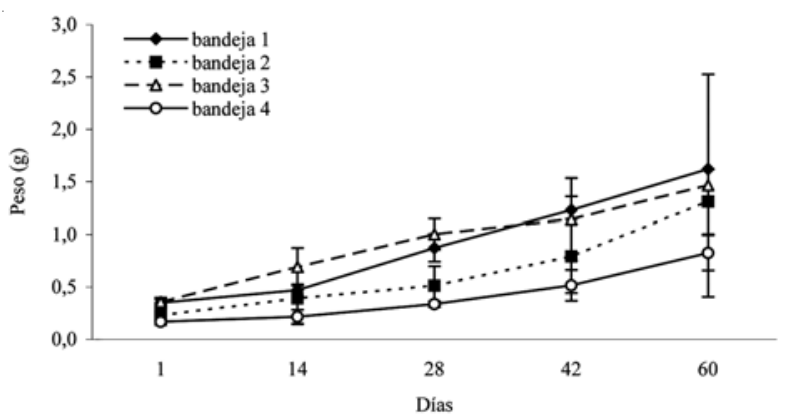

Figura 3

Crecimiento en peso (g) de juveniles de centollo a una densidad de 11 centollos $\mathbf{m}^{-2}$

Growth in weight (g) of juvenile spider crabs cultured at a culture density of 11 spider crabs $\mathrm{m}^{-2}$

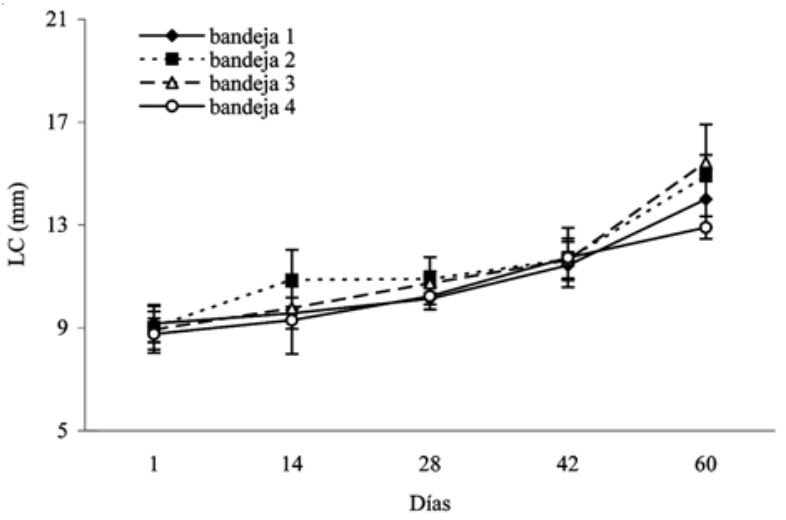

Figura 4

Crecimiento en longitud del caparazón ( $\mathrm{mm}$ ) de juveniles de centollo cultivados a una densidad de 11 centollos $\mathbf{m}^{-2}$

Growth in carapace length ( $\mathrm{mm}$ ) of juvenile spider crabs cultured at a density of 11 spider crabs $\mathrm{m}^{-2}$ 
diferencias estadísticamente significativas $(P>0,05)$ entre ellas. De igual manera, no hubo diferencias estadísticamente significativas $(P>0,05)$ en las tasas de crecimiento relativas a la longitud del caparazón, que fueron de $0,6 \pm 0,2 \% \mathrm{~L} \mathrm{~d}^{-1} ; 0,7 \pm 0,3 \% \mathrm{~L} \mathrm{~d}^{-1} ; 0,8 \pm 0,2 \% \mathrm{~L} \mathrm{~d}^{-1} \mathrm{y}$ $0,6 \pm 0,3 \% \mathrm{~L} \mathrm{~d}^{-1}$, para cada uno de los cuatro replicados, respectivamente.

\section{Discusión}

La determinación de los efectos de la densidad en un cultivo de especies marinas es de vital importancia, particularmente cuando se trata de especies con ciertas tendencias caníbales. El centollo M. brachydactyla presenta características caníbales tanto en los estados adultos como juveniles (Alaminos \& Domingues 2007) tras el proceso de muda, cuando el nuevo caparazón no está del todo endurecido y el animal está vulnerable al ataque de otros congéneres.

Durante el presente trabajo se observaron episodios de canibalismo relacionados con la densidad de cultivo, aunque la mortalidad total fue debida probablemente a dos factores. En primer lugar, la tasa de mortalidad en un cultivo en bandejas aumenta por simple cuestión estadística, cuando hay más individuos por bandeja y, en segundo lugar, a mayores densidades se incrementa la probabilidad de encuentros, lo que hace más vulnerables a los animales recién mudados. De hecho, la mayor mortalidad en las bandejas ocurrió después de la muda (96\%), bien causada por episodios de canibalismo o bien causada por el propio estrés de la muda. Fue raro encontrar centollos muertos con el caparazón duro, es decir que la causa de la muerte no estuviera de alguna forma relacionada con el proceso de muda.

Los episodios de canibalismo fueron importantes, particularmente en las bandejas con alta densidad de centollos. De hecho, en las densidades de 11 centollos $\mathrm{m}^{-2}$, fueron comidos por sus congéneres menos del $25 \%$ de los animales muertos, mientras que la tasa se elevó hasta el $60 \%$ para la más alta densidad, de 50 centollos $\mathrm{m}^{-2}$. Existe pues una asociación directa entre el canibalismo y la densidad de cultivo. De todas formas, el canibalismo puede haber sido activo (individuos muertos tras la muda como consecuencia de ataques directos de sus congéneres) o pasivo (fallecidos a causa de otros procesos (muda) y posteriormente comidos los cadáveres por sus congéneres). Esta dualidad es difícil de esclarecer, pues para determinar el tipo de canibalismo sería necesaria una observación continua de los tanques para determinar el momento exacto en que el animal es comido y comprobar si está vivo y muere como consecuencia del ataque, o se trata de un cadáver que ya ha muerto por otra causa. De todas formas es de hacer notar la elevada mortalidad ocurrida después de la muda, lo que no dependió de la densidad de cultivo.

Para los juveniles de centollo de menos de dos meses de edad y 9,0 $\pm 0,1 \mathrm{~mm}$ de longitud del caparazón, la densidad de cultivo que ha dado mejores resultados se establece en torno a los 10 individuos $\mathrm{m}^{-2}$. La supervivencia en las bandejas de menor densidad después de dos meses de experimentación (11 centollos $\mathrm{m}^{-2}$ ) fue alta (83\%) y la densidad final se centró en torno a este valor. Sin embargo, en las densidades de 32 centollos $\mathrm{m}^{-2} \mathrm{y}$ de 50 centollos $\mathrm{m}^{-2}$ la supervivencia fue inferior al $80 \%$ en el primer caso (tanto en presencia como ausencia de algas) y al 65\% en el caso de la más alta densidad.

Al día de hoy hay pocos datos sobre crecimiento de Maja brachydactyla. Corgos et al. (2007) ofrecen resultados en condiciones de laboratorio o en cultivos extensivos. Datos de crecimiento sobre otras especies de Maja fueron ofrecidos por Drach (1939), González Gurriarán et al. (1995), Iglesias et al. (2002) y Sánchez et al. (2007) mientras que Le Foll (1993) y Corgos et al. (2007) refieren datos sobre crecimiento en el medio natural.

No obstante, la mayoría de los datos que existen se ocupan del crecimiento de adultos y vienen expresados en \% de incremento en la longitud del caparazón, lo que es sólo apreciable si el animal muda. Los resultados que se ofrecen en el presente trabajo están expresados en incremento de peso durante un intervalo de tiempo fijo (15 días) y no en incremento de peso entre mudas (variable, por la gran variabilidad que existe en los periodos de intermuda), por tanto, no son posibles las comparaciones directas con los resultados de crecimiento de Maja sp. publicados en la bibliografía existente. Los únicos datos que podrían ser comparables sobre este aspecto han sido ofrecidos por Iglesias et al. (2002), que obtuvieron adultos (66\% de supervivencia), con longitud del caparazón de 6,5 $\pm 0,8 \mathrm{~cm}$ a los 9,5 meses de edad, en condiciones de cultivo semi-intensivo a temperaturas entre $15 \mathrm{y} 18^{\circ} \mathrm{C}$. Estos datos se corresponden con una tasa de crecimiento de $0,5 \% \mathrm{P} \mathrm{d}^{-1}$, menor que la obtenida durante este experimento, la cual fue entre 0,6 y $0,8 \% \mathrm{P}$ $\mathrm{d}^{-1}$. No obstante, es conocido que en todas las especies la tasa de crecimiento depende en gran medida del tamaño de los individuos, siendo más alta en individuos jóvenes, al inicio del ciclo de vida, y disminuyendo progresivamente a medida que el individuo crece. Por ello, animales pequeños como los utilizados en este trabajo, deben tener una tasa de crecimiento más alta que los individuos mayores de Iglesias et al. (2002), aunque este efecto no se ha visto especialmente reflejado. Por otro lado, las temperaturas de cultivo utilizadas en nuestros 
experimentos (en torno a los $20 \pm 2^{\circ} \mathrm{C}$ ) fueron más altas que las empleadas por Iglesias et al. (2002) $\left(15-18^{\circ} \mathrm{C}\right)$, lo que unido a lo anteriormente indicado sobre la tasa de crecimiento, puede ser un indicativo de que temperaturas más bajas proporcionan mayor crecimiento a esta especie.

A pesar de todo, las tasas de crecimiento son lo suficientemente interesantes como para avanzar en el conocimiento de Maja brachydactyla y hacer de ella una candidata a su cultivo a gran escala, particularmente en regiones templadas, de latitudes medias. En estas zonas las bajas temperaturas del agua impiden una acuicultura competitiva a la de especies de peneidos u otros crustáceos con altas tasas de crecimiento en aguas tropicales. Todo ello nos anima a estudiar con más profundidad estos asuntos y en próximos experimentos se probarán los efectos de la temperatura y de diversas dietas naturales (frescas o congeladas) y artificiales (piensos comerciales), sobre el crecimiento, supervivencia y el proceso de muda en la especie de centollo Maja brachydactyla.

\section{Agradecimientos}

Los autores agradecen al 'Plan Nacional de Centolla'JACUMAR - Proyecto 'Cría de centolla, Maja sp.’ 20072008 y al proyecto ‘Cooperación Algarbe-Andalucía para la promoción de recursos acuícolas marinos en el litoral suratlántico’ PROMAR (SP5.117/03) del Interregional INTERREG III A (European Regional Development Fund). Asimismo, agradecen a los evaluadores la labor de revisión del manuscrito y las sugerencias realizadas.

\section{Literatura citada}

Alaminos J \& P Domingues. 2007. Effects of different natural or prepared diets on growth and survival of juvenile spider crabs, Maja brachydactyla (Balss, 1922). Aquaculture International. DOI 10.1007/s10499-007-9154-6.

Bernárdez C, J Freire \& E González-Gurriarán. 2000. Feeding of the spider crab Maja squinado in rocky subtidal areas of the Ría de Arousa (North-West Spain). Journal of the Marine Biological Association of the United Kingdom 80: 95-102.

Boal JG, RA Hylton, SA González \& RT Hanlon. 1999. Effects of crowding on the social behaviour of cuttlefish (Sepia officinalis). Contemporary Topics in Laboratory Animal Science 38(1): 49-55.

Carlisle DB. 1957. On the hormonal inhibition of moulting in decapod crustacea. II. The terminal anecdysis in crabs. Journal of the Marine Biological Association of the United Kingdom 36: 291-307.

Chang ES. 1989. Endocrine regulation of moulting in Crustacea. Reviews in Aquatic Sciences 1: 131-157.

Conan GY, M Comeau \& G Robichaud. 1992. Life history and fishery management of majid crabs: The case study of the Bonne Bay (Newfoundland) Chionoectes opilio population. ICES, Shellfish Communication Conférence Mondiale 1992/K: 21-24.

Corgos A, MP Sampedro, E González-Gurriarán, J Freire 2007. Growth at moult, intermoult period and moulting seasonality of the spider crab Maja brachydactyla: combining information from mark-recapture and experimental studies. Journal of Crustacean Biology 27: 255-262.

Domingues P, R Poirier, L Dickel, E Almansa, A Sykes \& P Andrade. 2003. Effects of culture density and live prey on growth and survival of juvenile cuttlefish, Sepia officinalis. Aquaculture International 11: 225-242.

Drach P. 1939. Mue et cycle d'intermue chez les crustacés décapodes. Annales de l’ Institut Océanographique 19: 103391.

Forsythe J, P Lee, L Walsh \& T Clark. 2002. The effects of crowding on growth of the European cuttlefish Sepia officinalis Linnaeus, 1758 reared at two temperatures. Journal of Experimental Marine Biology and Ecology 269(2): 173-185.

González-Gurriarán E \& J Freire. 1994. Movement patterns and habitat utilization in the spider crab Maja squinado (Herbst) (Decapoda: Majidae) measured by ultrasonic telemetry. Journal of Experimental Marine Biology and Ecology 184: 269-293.

González-Gurriarán E, J Freire, J Parapar, MP Sampedro \& M Urcera. 1995. Growth at moult and moulting seasonality of the spider crab, Maja squinado (Herbst) (Decapoda: Majidae) in experimental conditions: Implications for juvenile life history. Journal of Experimental Marine Biology and Ecology 189: 183-203.

González-Gurriarán E, J Freire \& C Bernárdez. 2002. Migratory patterns of female spider crabs Maja squinado detected using electronic tags and telemetry. Journal of Crustacean Biology 22(1): 91-97.

Hartnoll RG. 1963. The biology of Manx spider crabs. Proceedings of the Zoological Society of London 141: 423496.

Hines AH, TG Wolcott, E González-Gurriarán, L GonzálezEscalante \& J Freire. 1995. Movement patterns and migrations in crabs: Telemetry of juvenile and adult behaviour in Callinectes sapidus and Maja squinado. Journal of the Marine Biological Association of the United Kingdom 75: 27-42.

Iglesias J, FJ Sánchez, C Moxica, L Fuentes, JJ Otero \& JL Pérez. 2002. Datos preliminares sobre el cultivo de larvas y juveniles de centolla Maja squinado Herbst, 1788 en el Centro Oceanográfico de Vigo del Instituto Español de Oceanografía. Boletín del Instituto Español de Oceanografía 18: 25-30.

Ingle RW. 1980. British crabs, 199 pp. Oxford University Press, London.

Kergariou G. 1971. L'araignee de mer, Maja squinado L., sur le litoral de Bretagne. Bulletin d’Institute des Pêches Maritimes 205: 11-19. 
Kergariou G. 1984. L'araignée de mer Maja squinado H., biologie et exploitation. La Pêche Maritime 1279: 575-583.

Le Bour MV. 1927. The larval stages of the Plymouth Brachyura. Proceedings of the Zoological Society of London 1: 473-560.

Le Foll D. 1993. Biologie et explotation de l'araignée de mer Maja squinado Herbst en Manche Ouest. Ph D thesis, Université de Bretagne Occidentale, Brest, 517 pp.

Sampedro MP, E González-Gurriarán, J Freire \& R Muiño. 1999. Morphometry and sexual maturity in the spider crab Maja squinado (Decapoda: Majidae) in Galicia, Spain. Journal of Crustacean Biology 19: 578-592.

Sampedro MP, E González-Gurriarán \& J Freire. 2003. Moult cycle and growth of Maja squinado (Decapoda:
Majidae) in coastal habitats of Galicia, north-west Spain. Journal of The Marine Biological Association of the United Kingdom 83: 995-1005.

Sánchez FJ, L Fuentes, J Iglesias, C Moxica \& JJ Otero. 2007. Crecimiento y ciclos de muda de la centolla (Maja squinado Herbst) en condiciones de cultivo. Foro de Recursos Marinos y de Acuicultura de las Rías Gallegas 9:213-215.

Sumpter JP. 1993. The deleterious effects of stress and their effects to aquaculture. En: Barnabé G \& P Kestemont (eds). Production, environment and quality. Special publication of the European Aquaculture Society 18: 157-166.

Zar JH. 1984. Biostatistical analysis. 619 pp. Prentice-Hall. Englewood Cliffs.

Recibido el 18 de septiembre de 2007 y aceptado el 31 de enero de 2008 